\title{
REINTEGRASI SAINS DAN ISLAM BAGI PRAKTISI PENDIDIKAN \\ (Suatu Tinjauan Epistimologi dan Aksiologi)
}

\author{
Usman \\ Jurusan Tarbiyah Sekolah Tinggi Agama Islam Negeri Kerinci STIT YPI Kerinci \\ Korespondensi: Jl. Pelita IV Sungai Penuh, Jambi. Telp (0748) 21065
}

\begin{abstract}
Science and Islam are basically one, under the domain of wahidat al-Wujud. Within the domain, knowledge (science) has same unity and value to the knowledge of Allah. However, as it reached the earth, multi-fragmentation took place due to different capacity of human brain where generically it has different shape and limitation. One brain compared to the other one has its own portion which is called individualistic differentiation. Such individualistic differentiation is the realization of differences, limitations, and perspectives which are different from one another and similarity as well.
\end{abstract}

Kata kunci: merajut kembali sains dan islam oleh praktisi pendidikan

\section{PENDAHULUAN}

$\mathrm{S}$ ains dan Islam adalah suatu ilmu yang merupakan satu wujud kesadaran, dan keyakinan ilmu, yang bersumber dari satu sumber yakni Allah Yang Maha Alim. Ketika Allah mengilhamkan ilmu itu kepada manusia. Lalu manusia itu, mengerti, memahami, meyakini, menyadari dan memakainya menurut perspektif kediriannya. Bisa saja kebenaran ilmu ada padanya dan salah pada orang lain, jika dilihat dari perspektif simbolistik, karena keterbatasan simbolistik itu sendiri. Akan tetapi bila dibuka dengan perspektif maknawi, bisa saja melahirkan wujud hasil yang sama. Tapi sayang, sampai sekarang ini antara sains dan Islam sudah semakin terasa bercerai, dan memiliki wujudnya masing-masing. Sains ia sains, dan Islam ia Islam.

Kita lihat dewasa ini, banyak anggapan masyarakat luas yang mengatakan bahwa sains dan Islam adalah dua en- titas yang berbeda bahkan tidak bisa dipertemukan. Keduanya mempunyai wilyah sendiri-sendiri, terpisah antara satu dengan yang lainnya, baik dari segi objek formal-material, metode penelitian, criteria kebenaran, peran yang dimainkan oleh pemakai (user) maupun status masing-masing, bahkan sampai kepada pihak penyelenggaranya. Dengan kata lain, agama tidak mempedulikan ilmu, dan ilmu tidak mempedulikan agama. Seperti manusia tengah dilanda talak dan bercerai. Begitulah kiranya gambaran sains dan Islam di tengah kehidupan dewasa ini.

Oleh karena itu, anggapan yang menyatakan bahwa adanya perceraian (perpisahan) antara sains dan Islam, perlu diarifi dengan integralistik-holistik. Tidak dalam formulasi fragmentasi. Adanya anggapan pemisahan ini adalah susupan yang dihembuskan oleh pahampaham "sekuler". (Barat)

Sejarah hubungan ilmu dan agama di Barat mencatat bahwa pemimpin 
gereja menolak Teori Helionsentris Galileo atau teori Evolusi Darwin. Pemimpin gereja membuat pernyataan yang berada diluar kompetensinya. Sebaliknya Isaac Newton dan tokoh ilmuilmu sekular menempatkan Tuhan hanya sekedar sebagai penutup sementara lobang kesulitan (to fill gaps) yang tidak terpecahkan dan terjawab oleh teori keilmuan mereka, sampai tiba waktunya diperoleh data yang lebih lengkap atau teori baru yang dapat menjawab kesulitan tersebut. Begitu kesulitan itu terjawab, maka secara otomatis intervensi Tuhan tidak lagi diperlukan. Akhirnya Tuhan dalam benak para ilmuan "sekuler" hanya ibarat pembuat jam (clock maker). Begitulah alam semesta ini selesai diciptakan, Ia tidak peduli lagi dengan alam raya ciptaanNya dan alam semestapun berjalan sendiri secara mekanis tanpa campur tangan tujuan agung ketuhanan (M. Amin Abdullah, 2003:3).

Sementara dalam dunia Timur (dunia Islam) pengajaran ilmu-ilmu agama Islam dilakukan secara normative-tekstual terlepas dari perkembangan sains dan teknologi, ekonomi, politik, hokum, psikologi, antropologi, sosiologi dan ilmu-ilmu humniora pada umumnya. Perbedaan ini semakin hari semakin nyata menunjukkan entitasnya masingmasing, ibarat deret ukur terbalik dan hasilnya membuat tidak nyaman bagi kehidupan dan kesejahteraan manusia. Paradigma pemikiran yang serba bipolar-dikotomis ini menjadikan manusia terisolasi dari nilai-nilai etik-spiritualitas dari dirinya sendiri. Hakikat dirinya akan terasing dari keluarga dan masyarakat sekelilingnya, terasing dari lingkungan alam dan ragam hayati yang menopang kehidupannya serta terasing dari denyut nadi lingkungan sosial-budaya sekitarnya. Singkatnya, terjadi proses dehumanisasi secara massif baik pada tataran kehidupan keilmuan maupun keberagamaan.
Semua ini adalah tugas berat yang dipikul oleh ilmuan muslim yang berkeyakinan bahwa semua ilmu berada dalam satu wilayah yakni wilayah keilmuan Allah Yang Maha Alim. Mau tidak mau ilmuan muslim mestinya berupaya mencari, merakit dan merujukkan kembali paradigma bipolar-dikotomis itu. Tugas berat ini, terutama dilakukan oleh praktisi pendidikan. Oleh karena itu, makalah ini mencoba memaparkan "Reintegrasi Sains dan Islam bagi Praktisi Pendidikan; Suatu Tinjauan Epistimologi dan Aksiologi”.

\section{SAINS DAN ISLAM}

Kata sains adalah bacaan dalam bahasa Indonesia, dan bacaan tersebut diambil dari tulisan bahasa Inggeris yakni "science" artinya ilmu pengetahuan atau cerita khayal yang bersifat ilmiah (John M. Echols dan Hassan Shadily, 1996:504). Kata ilmu pengetahuan atau "sains" dalam bahasa Indonesia memiliki beberapa padanan kata dalam bahasa asing, antara lain: science (dalam bahasa Inggeris, wissenschift (Jerman) atau wetenschap (Belanda). Sedangkan yang dimaksudkan dengan pengertian science,__ tanpa adanya keterangan lebih lanjut _, adalah $n a$ tural science atau ilmu kealaman'. Natural science merupakan ilmu yang mempelajari fenomena-fenomena alam semesta dengan segala isinya, dan yang termasuk natural science (selanjutnya disebut science) adalah ilmu-ilmu dasar '(basic science), disebut pula dengan ilmu-ilmu murni '(pure science), seperti biologi, kimia, fisika, dan astronomi, dengan segala cabangnya. Derivasi dari basic science adalah applied science atau ilmu-ilmu terapan', yaitu farmasi, kedokteran, pertanian dan lain-lain (M. Amin Abdullah, 2003: 106).

Kata ilmu dalam bahasa Indonesia berasal dari bahasa Arab yakni 'ilm yang merupakan kata jadian dari kata alima 
yang berarti 'tahu atau mengetahui. Raharjo mencatat pendapat orientalis Franz Rosethal, bahwa akar kata ' $a-l-m$ dalam bahasa Arab tidak mempunyai persamaan dengan kata bahasa Semitik lainnya, walaupun bahasa Arab termasuk kedalam rumpun bahasa Semitik. Akar kata ' $a-l-m$ dalam bahasa Semit mempunyai arti 'tanda' (ayat). Ini menimbulkan kesan bahwa terdapat kaitan antara 'tahu' dengan 'tanda' (ayat) dalam bahasa Arab. 'pengetahuan tentang tanda' (ayat) atau 'mengetahui' ayat'. Yang dimaksudkan dengan 'tan$d a$ ' atau ayat dalam konteks pengetahuan adalah 'fenomena-fenomena alam dengan segala isinya'.

Berdasarkan pengertian di atas, dapatlah diberikan definisi tentang ilmu pengetahuan (sains) yaitu himpunan pengetahuan manusia tentang alam yang disimpulkan secara rasionl dari hasilhasil analisis kritis terhadap data-data pengukuran yang diperoleh melalui pengamatan (observation) pada fenomena-fenomena alam. Bila dikaitkan dengan tekonologi. Tekonologi adalah himpunan pengetahuan manusia tentang proses-proses pemanfaatan alam yang diperoleh dari penerapan sains, dalam kerangka kegiatan produktif -ekonomis.

Kata Islam itu dipahami dalam bentuk masdar. Fi'il kata kerjanya adalah aslama (madhy/past tense)- yuslimu (mudhari'/present tense atau future tense), yang searti dengan inqada (نقاد) dan kadla'a (خغ ) yang berarti tunduk, patuh, dan menyerah, dan juga berarti memeluk agama Islam (Louis Ma'luf, tt:257). Jadi kata Islam dari segi etimologi berarti inqiyad (انقياد) dan Khudlu' (خضو), yakni sikap tun-duk, taat dan menyerah/pasrah.

Sedangkan makna Islam dilihat dari segi terminology (istilah) banyak pakar yang telah mengartikannya, antara lain dikatakan bahwa Islam berarti sikap tunduk kepada perintah pemberi amaran (perintah) dan larangannya tanpa melakukan protes atau perlawanan. Sementara Ibn Taimiyah mengartikan Islam sebagai sikap menyerah-pasrah kepada Allah, tidak kepada yang lain (Nurcholis Madjid, 1995: xiii). Sedangkan Sayyid Quttub antara lain mengatakan bahwa Islam adalah sikap taat dan patuh mengikuti dan menjadikan alQur' an sebagai sumber hokum untuk diterapkan di dalam semua urusan (Sayyid Quthb, 1978: 206).

Dari ketiga pengertian terminologi tersebut dapatlah diketahui bahwasanya pengertian yang pertama sifatnya masih sangat umum, sehingga sifat tunduk dan patuh kepada seseorang pun dapat dikatakan sebagai sikap islami. Maksud esensi dari redaksinya masih sangat berdekatan dengan makna etimologinya. Jadi pengertian tersebut masih bersifat Profan, artinya belum menyentuh sisi syari'at kenabian, yang berintikan ketauhidan. Sementara pengertian yang kedua, dari Ibnu Taimiyah sudah meninggalkan jauh yang pertama. Mengapa? Karena kepasrahan yang dimaksud sudah mengarah kearah pentauhidan (ke-Tuhan-an Yang Maha Esa). Meskipun begitu pengertian tersebut masih bersifat lebih umum apabila disbandingkan dengan pengertian yang ketiga. Keislaman yang terkandung dalam pengertian yang kedua cakupannya sangat luas, mencakup keislamannya para nabi dan rasul sebelum Nabi Muhammad SAW. dan bahkan secara ekstrim sikap "keislaman" (kepasrahan) tersebut boleh jadi dapat dilakukan oleh orang-orang di luar umat Muhammad SAW. Jadi sifat tahdidi (pembatasan)-nya belum ketat, artinya masih mengandung unsure inklusivitas. Pengertian ini bisa dipahami karena intinya masih paralel dengan makna keberserahan diri yang terkandung dalam firman Allah yang berbunyi: 


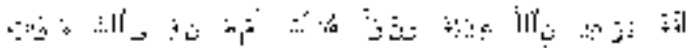

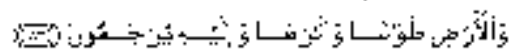

Maka apakah mereka mencari agama yang lain dari agama Allah, padahal kepada-Nya-lah berserah diri segala apa yang di langit dan di bumi, baik dengan suka maupun terpaksa dan hanya kepada Allahlah mereka dikembalikan.. (QS. Ali Imran/3: 83)

Sedangkan yang ketiga bersifat sangat khusus dan ekslusif. Hal ini dapat dipahami dari redaksinya yang cukup eksplisit, yaitu dengan disebutkannya kepatuhan penuh kepada ketentuanketentuan hokum dalam al-Qur' an. Jadi yang dimaksudkan dengan Islam dalam pengertian yang ketiga ini adalah (syariat) Islam yang dibawa oleh Nabi Muhammad SAW. Mengapa demikian? Karena pengertian ketiga ini menekankan pengamalan ajaran-ajaran al-Qur'an dimana diketahui bahwa al-Qur'an adalah Kitab yang diturunkan Allah kepadanya, dan ia dijadikan sebagai petunjuk dan pedoman utama bagi umat Islam, pengikut Muhammad SAW. Benang merah substansi pengertian ketiga ini sejalan dengan apa yang difirmankan Allah SWT. yang berbunyi:

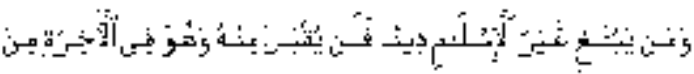

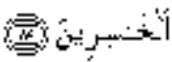

Barangsiapa mencari agama selain agama Islam, maka sekali-kali tidaklah akan diterima (agama itu) daripadanya, dan dia di akhirat termasuk orang-orang yang rugi. (QS. Ali Imran/3: 85).

Dari pengertian-pengertian tersebut, baik dilihat dari segi etimologi maupun terminologi serta pemahaman terhadap ayat-ayat al-Qur'an di atas, maka dapatlah diambil suatu pengertian bahwa yang dimaksud dengan (agama) Islam adalah sikap berserah diri atau taat secara ikhlas kepada Allah dengan mengikuti syari'at Nabi Muhammad
SAW. yang berpedoman kepada alQur'an dan hadits, demi mendapatkan kehidupan yang selamat dan sejahtera di dunia dan di akhirat.

Islam adalah agama universal. Ia memiliki kandungan yang luas, memiliki nilai fungsional ketaatan, kepasrahan, kesejahteraan dunia dan akhirat, dengan dasar nilai adalah tauhidik. Islam adalah system nilai yang dimiliki dan diyakini orang muslim dalam kehidupannya. Islam menyintuh berbagai dimensi baik dalam dimensi material, maupun inmaterial.

\section{GURU TENGAH REINTEGRASI SAINS DAN ISLAM DALAM PEN- DIDIKAN; TELAAH EPISTIMO- LOGI DAN AKSIOLOGI}

\section{Guru}

Kata Guru adalah kata simbolik yang diberikan oleh orang atau banyak orang kepada seseorang yang melakukan tugas fungsionalnya dalam pendidikan. Ada beberapa sinonim dari kata yang setara dengan guru, baik dalam perspektif filosofis-ontologis maupun epistimologis-aksiologis. Perspektif filosofis-ontologis, dalam bahasa Inggeris, guru disebut dengan educator, teacher atau instructor. Bahasa Arab menyebutnya dengan kata murabbi, muallim, mu'addib, muhazzib, muzakki dan mudarris. Sedangkan perspektif epistimologis-aksiologis, dalam praktisi pendidikan formal (persekolahan) mulai dari Taman Kanak-kanak, sekolah dasar, sekolah menengah pertama dan sekolah menengah atas disebut guru. Untuk perguruan tinggi seseorang yang melakukan tugas fungsionalnya dalam pendidikan disebut dosen. Dalam pendidikan nonformal (lingkungan masyarakat) disebut buya, kiyai, ustadz, mursyid, tutor, pelatih, pembimbing dan lain-lain. Namun, Intipati dari semua kata simbolik itu adalah menjalankan amanah membantu me- 
layani pertumbuhan dan perkembangan multi potensi yang dimiliki oleh masingmasing individu (peserta didik) menuju kedewasaan. Untuk memudahkan pengertian, pemahaman, dan menyatukan persepsi, penulis dalam menyajikan paparan makalah ini mengambil satu kata symbol, yakni guru dan dengan kata symbol ini agaknya bisa mewakili katakata symbol yang lain.

Guru adalah nama panggilan bagi orang yang melaksanakan tugasnya dalam praktisi pendidikan secara proporsional dan profesional. Pada hakikinya tidak mudah seseorang itu mendapat sebutan guru. Tugas guru sesungguhnya amatlah berat, karena ia bertugas menyampaikan banyak pesan, di antaranya pesan pengetahuan (kognitif), pesan nilai (afektif), pesan perilaku, keterampilan dan akhlak, serta seni (Psikomotorik). Ia sadar bahwa ketika sedang melaksanakan tugas pendidikan, ia sedang mewariskan dirinya kepada peserta didik, tidak bisa dipungkiri bahwa guru masih tetap idola bagi peserta didik. Guru adalah seorang figure model bagi peserta didik. Karena itu, guru yang ideal adalah yang memenuhi persyaratan baik persyaratan personaliti maupun akademisi.

Dua persyaratan tersebut perspektif pendidikan Islam adalah (1) personaliti: guru memiliki integralistik tauhidik yang holistic, zuhud, tawakkal, pemaaf, memiliki rasa kasih sayang pada peserta didik, bersih lahir batin (tidak sombong, takabbur, ria dll.) memiliki niat dan harapan yang besar terhadap keberhasilan peserta didik, mampu menjadikan dan menkondisikan bahwa yang belajar itu adalah anak dirinya sendiri, hendaknya menjauhi mata pencaharian yang hina (haram) dan menjauhi situasi yang mendatangkan fitnah dan tidak melakukan sesuatu yang dapat menjatuhkan harga dirinya, hendaknya guru tidak berorientasi duniawi dengan menjadikan ilmunya sebagai alat untuk mencapai ke- dudukan, harta dan prestise, guru hendaknya selalu mengisi waktu-waktu luangnya dengan hal-hal yang bermanfaat, seperti beribadah, membaca dan mengarang, guru hendaknya tidak merasa malu belajar terhadap siapaun juga, meskipun kepada orang yang usianya lebih rendah dari dirinya dan lain-lain. (2) akademisi: guru memiliki perencanaan terhadap pembelajaran, guru menguasai tujuan dan ilmu yang akan diajarkannya, guru menguasai metodologi, (metode, manejemen ilmu, manajemen kelas, dinamika kelas dan ilmu komunikasi), guru menguasai filsafat evaluasi dan mampu mengimplementasikannya.

Agaknya ini di antaranya yang perlu dimiliki oleh guru ketika hendak menjadi praktisi pendidikan di lapangan. Apalagi guru di era globalisasi, tugasnya semakin berat menghadapi tantangan yang begitu deras bergulir semakin hari semakin menanjak prakmentasinya, sudah berserakan dan memiliki masingmasing entitas. Banyak anggapan masyarakat bahwa masing-masing ilmu itu sudah tidak lagi bersintuhan dan bahkan tidak bisa dirujuk dan disatukan lagi, seperti, politik, ekonomi, antropologi, sosiologi, biologi, fisika matematik, bahasa, agama dan ilmu pengetahuan lainnya. Masing-masing ilmu pengetahuan itu memiliki entitasnya sendiri, tidak bersintuhan satu dengan yang lainnya. Padahal bila dirujuk dalam sejarah ilmu pengetahuan. Semuanya berasal dari satu sumber Yang Maha Sumber yaitu Allah SWT. Al-Qur'an menjelas dalam surat al-Baqarah/2: 31 yang berbunyi:

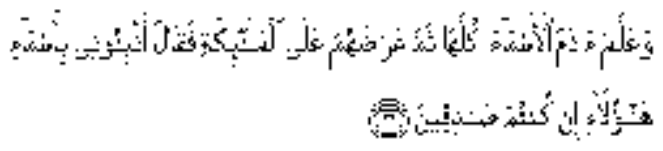

Dan Dia mengajarkan kepada Adam nama-nama (benda-benda) seluruhnya, kemudian mengemukakannya kepada para Malaikat lalu berfirman: "Sebutkanlah kepada-Ku nama ben- 
da-benda itu jika kamu memang orang-orang yang benar!". (QS. AlBaqarah/2:31)

Dari ayat di atas ini jelaslah 'bahwa ilmu pengetahuan berasal dari Allah SWT. Yang diwahyukan langsung pada hamba-Nya, Adam a.s. Ilmu ini dibekalkan kepada Adam a.s. agar ia mampu berkomunikasi dengan lingkungannya.

Dalam catatan historis kenabian, terutama dalam tafsir Fath al-Qadir, Idris a.s. adalah seorang Nabi yang diberkati ilmu pengetahuan yang banyak oleh Allah SWT. Dia mengetahui tentang ilmu Fisika, Astronomi, Ilmu Tulis dan lain sebagainya. Begitu pula Nabi Syis a.s., putra Nabi Adam a.s. diberkati pula dengan bakat ilmiah. Nama Idris Maupun Syis sangat dikenal oleh masyarakat purba di wilayah Timur Tengah sebagai pembawa ilmu pengetahuan (M. Amin Abdullah, 2003: 109). Oleh karena itu, Allahlah pemilik semua ilmu pengetahuan baik yang ada di langit, di bumi maupun yang ada pada semua isinya. Ialah yang Maha Alim (berilmu pengetahuan). Ketika semua ilmu itu tengah berada dalam wilayah ke-ilahi-an, ia adalah satu entitas, yakni entitas keTuhan-an. Tapi tatkala ilmu itu sampai pada makhluk-Nya manusia. Disinilah mulai berdiri entitas masing masing. Manusia melihatnya perspektif otaknya masing-masing yang serba diferensiasi dan terbatas. Maka sesuatu yang dilihat dan dibaca itu adalah menurut daya otaknya sendiri tanpa adanya pertalian satu dengan yang lain. Perserakan yang serba bipolar-dikotomis menjadi kewajiban dan tanggung jawab bagi kaum ilmuan muslim terutama praktisi pendidikan kiranya dapat merujuk dan menyatukan kembali agar ia berada dalam payung tauhidik teosentrik.

\section{Epistimologi dan Aksiologi Re- integrasi Sains dan Islam bagi Praktisi Pendidikan}

Islam memandang kehidupan sosial, ekonomi, politik dan lain-lain sekurangnya, selain merupakan hasil atau bentuk interaksi antar manusia, sekaligus mengandung nilai dan fungsi trasendental, yaitu ibadah. Ketika manusia bersosialisasi dengan keanekaragaman ilmu, nilai transedental tauhid merupakan dasar interaksinya. Nilai trasedental merupakan tanggung jawab bagi setiap praktisi pendidikan dalam tujuan profetik. Praktisi bukan hanya mendorong transformasi, tapi lebih mengarah kepada sebuah tatanan social berkeadilan dan berkemakmuran yang ma'ruf. Dari sinilah doktrin social tentang amanah bisa difungsikan bagi tujuan kolektif (social) dan vertical (tauhid) yang syarat dengan kepentingan personal, komunal dan factual. Disinilah terletak fungsi rahmatan lil alamin.

Teologi profetik mengharuskan rekonstruksi kesatuan ilmu berdasarkan prinsip kesadaran trasedental. Ilmu-ilmu yang selama ini disebut umum (sains) ditempatkan ke dalam "ilmu-ilmu Islam", atau sebaliknya Ilmu-ilmu Islam ditempatkan ke dalam ilmu umum (sains), sehingga tidak terjadi dikotomis. Ia adalah satu kombinasi yang universal.

Bangunan Teologi profetik epistimologi dan aksiologi bagi praktisi pendidikan sangat dibutuhkan agar sasaran yang hendak dicapai dapat diwujudkan.

Bangunan tersebut adalah berawal dari dasar/sendi, materi, metodologi, dan evaluasi.

\section{Dasar Atau Sendi}

Dasar atau sendi epistimologiaksiologi reintegrasi sains dan Islam bagi praktisi pendidikan adalah tauhidik. Tauhid bukan hanya eksistensinya ada dalam ilmu teologi-ibadah praktis, seperti mengucapkan dua kalimat shahadat, shalat, zakat, puasa dan haji, akan 
tetapi eksistensinya sangat luas. Ia ada dalam ilmu-ilmu lain, seperti filsafat, sosiologi, antropologi, matematik, bahasa, biologi, dan lain-lain. Sebagaimana dikemukakan oleh Musa Asy'ari dalam tulisannya, bahwa Prinsip ajaran tauhid dalam Islam pada hakikatnya tidak hanya berhubungan dengan konsep teologi semata, tetapi ia juga melingkupi konsep kosmologi, antropologi, aksiologi dan termasuk di dalamnya juga epistimologi (M. Anas Amin dan Mustofa, 2003, 30). Karena itu tauhid yang seakar dengan angka satu, wahidah tidak merujuk pada angka satu saja, tetapi lebih dari itu, juga berkaitan masalah substansi tunggal dan proses. Substansi tunggal artinya tidak terbagi-bagi. Ia menjadi sumber rialitas yang ada; di dalam termuat dalam suatu keseluruhan. Sedangkan proses pada makna tauhid di atas, berarti proses kesatuan dari keanekaragaman yang ada dalam realitas kehidupan.

Dari berbagai keanekaragaman ilmu-ilmu, misalnya ilmu teknologi, ilmu, botani, ilmu hewani, nabati, mantic, ilmu politik, ekonomi, pertanian, perdagangan, agama atau ilmu-ilmu humaniora lainnya, bangunan dasar atau sendinya adalah tauhid. Tauhidlah akar dari bangunan epistimologi-aksiologi. Guru membangun wawasan keanekaragaman ilmu itu dengan bangunan tauhid. Tauhidlah menjadi sendi etik-moralitik epistimologi dan aksiologi. Sehingga pertumbuhan dan perkembangan keanekaragaman ilmu-ilmu berada dalam payung tali yang kokoh yakni tauhid. Di samping itu, Prinsip dari proses-proses itu adalah beribadah kepada kepada Allah SWT. Bukan semata mencari kekayaan pengetahuan (knowledge) belaka. Ia sadar bahwa sedang, menumbuh subur potensi-potensi yang dimilikinya dalam menjalankan tugasnya di muka bumi (khaalifah fi al-ardh). Prinsip ini merupakan pendekatan diri kepada Allah
SWT. Oleh karena itu, ilmu-ilmu yang terpartisi itu, hendaknya dirujuk dan disatukan kembali dalam satu proses ketunggalan tauhid.

\section{Materi Reintegrasi Sains dan Islam}

Penentuan materi dalam menuju suatu tujuan sangatlah penting, karena kalau materi itu tidak mendukung tujuan, maka tujuan itu tidak akan didapatkan. Oleh karena itu, seorang guru mestinya harus hati-hati menentukan materi yang akan ditranformasikan itu, agar materi itu bisa larut dan sampai dalan satu tujuan.

Materi dasar dari bangunan reintegrasi epistimologi-aksiologi itu adalah dengan mengintegrasikan ayat-ayat Allah, yaitu:

1). Ayat-ayat Allah yang termuat dalam al-Qur' an (ayat al-qur'aniayah)

2.) Ayat-ayat Allah yang ada di alam, (ayat al-kauniyah) dan

3.) Ayat-ayat Allah yang ada pada manusia (ayat al-insaniyah)

Dari ketiga ayat Allah inilah, basic formulasi-aktualisasi reintegrasi. Ketiga ini berasal dari satu sumber, yakni Allah SWT.

Al-din Islam, al-Qur'an adalah kitab agama bukan kitab filsafat, terhadap teori sains, al-Qur'an memberikan gambaran yang secara urut mempunyai skala yang menaik, yaitu:

1. 'Ilmu al-yaqin (QS. Al-Takatsur/102: 5).

2. 'Ain al-yaqin (QS. Al-Takatsur/102: 7).

3. Haqq al-yaqin (QS. Al-Haqqah/69: 51).

Ketiga bentuk pengetahuan ini tidak harus berkontroversi, satu dengan yang lainnya, tetapi harus konsisten secara structural menurut bagan di bawah ini: 


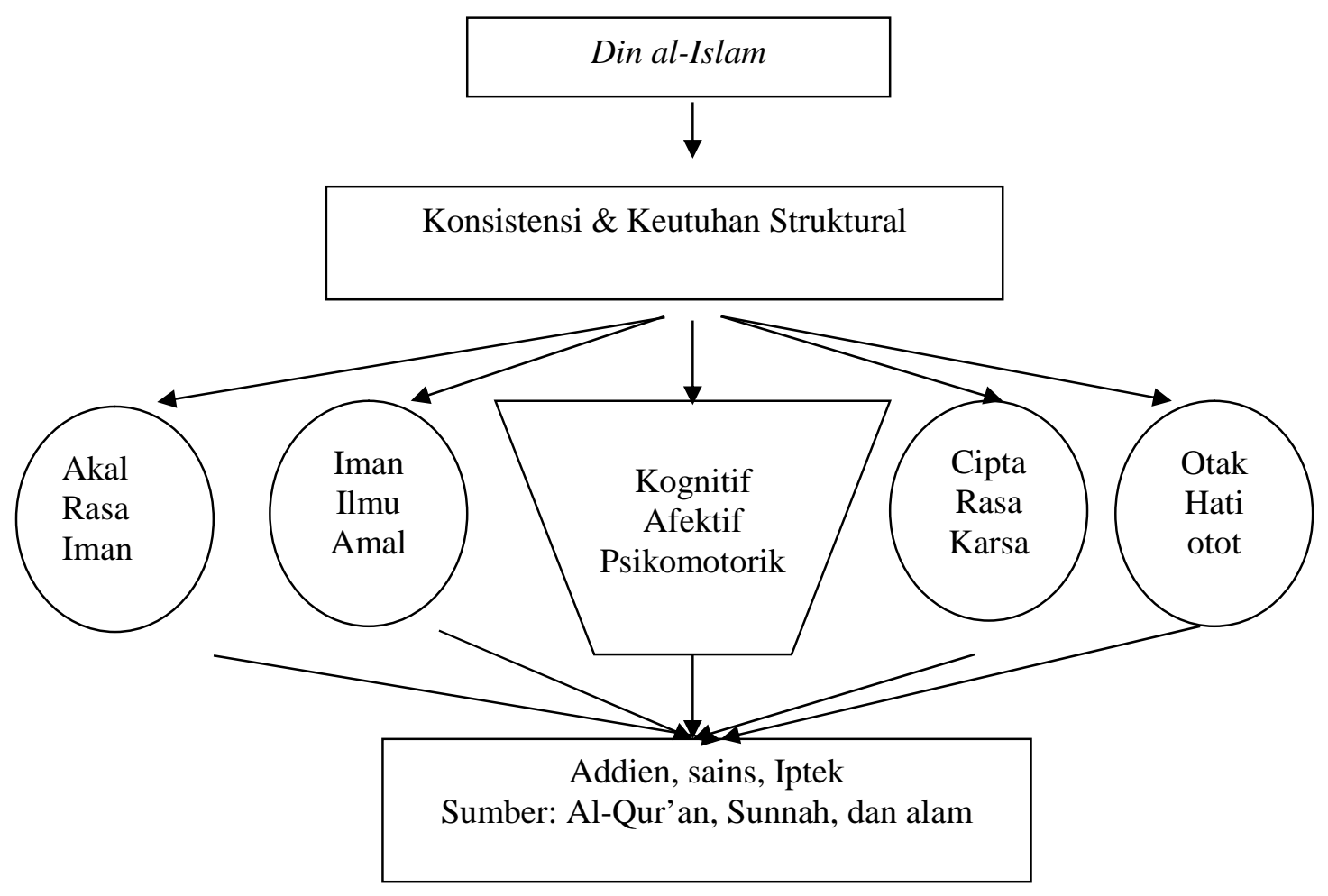

Bagan di atas ini menunjukkan adanya persatuan ilmu, yakni antara akal, rasa dan iman, antara iman, ilmu dan amal, antara kognitif, afektif dan psikomotorik, antara cipta, rasa, dan karsa, dan antara otak, hati dan otot. Semua ini termuat dalam Addien, sains dan Iptek yang bersumber pada al-Qur'an, Sunnah dan alam.

Jadi materi dasar bangunan epistimologi-aksiologi reintegrasi adalah berangkat dari al-Qur' an, hadits dan alam. Nuansa sumber ini menyusupi dan menuansai seluruh pragmentasi keilmuan. Al-Qur'an dan hadits ini menjadi dasar materi dalam berbagai etika aksiologi pendekatan (etic approachment). Jadi sehingga tidak lagi berjarak antara sains dan Islam. Ibarat robot, sains robotnya dan Islam energinya. Sains jasadnya dan Islam rohnya.

\section{Pendekatan Metode Approach-Ment)}

(Methode

Metode yang dipergunakan oleh seseorang dalam menyampaikan materi kepada tujuan sangatlah penting, sehingga ada statemen mengatakan: الطريقة metode itu lebih penting dari pada materi. Maka sangatlah penting untuk mengetahui dan melakukan pendekatan metode yang tepat, efektif dan efisien. Pendekatan metode itu agaknya dapat menyampaikan pesan pesan keilmuan, nilai, ethic, moral dan spiritual.

Untuk mendapati ini, setidaktidaknya ada dua macam kurikulum yang dapat dimanfaatkan dalam reintegrasi sains dan Islam. Dua kurikulum itu adalah kurikulum tertulis (written curriculum) dan kurikulum tersembunyi (hidden curriculum).

Kurikulum tertulis adalah mengikuti apa saja yang telah dirancang dalam tulisan kurikulum itu, seperti yang ada dalam silaby atau GBPP. Kurikulum tertulis ini agaknya lebih focus menyampaikan pesan-pesan kognitif dan psikomotorik, dan kurang menyintuh pesan ethic, moralitik dan spiritualistik. Sedangkan kurikulum tersembunyi adalah kurikulum yang tidak tertulis dalam kurikulum tertulis, dan ia sangat perlu disampaikan. Kurikulum tersembunyi ini lebih focus menyampaikan pesan nilai, 
ethic, moral dan spiritual. Sehingga dalam pendekatan ini dua kurikulum tersebut dapat dipakai. Satu sama lain saling menopang.

Wawasan tauhid dalam epistimologi Islam yang disumberkan kepada alQur'an sudah barang tentu menuntut suatu metodologi yang memungkinkan wawasan tauhid itu dapat diaktualisasikan secara konkret dalam realitas kehidupan. Kali ini diturunkan, QS. Al'Alaq/96: 1-5, yang menegaskan suatu cara membaca realitas atas nama $\mathrm{Tu}-$ han yang menciptakan, atau membaca dengan kesadaran kehadiran Tuhan dalam objek realitas. Dalam kaitan ini, secara operasional QS. Ali Imran/3 190191, menjelaskan:

Sesungguhnya dalam penciptaan langit dan bumi, dan silih bergantinya malam dan siang terdapat tandatanda bagi orang-orang yang berakal. (yaitu) orang-orang yang mengingat Allah sambil berdiri atau duduk atau dalam keadaan berbaring dan mereka memikirkan tentang penciptaan langit dan bumi (seraya berkata): "Ya Tuhan kami, tiadalah Engkau menciptakan ini dengan sia-sia. Maha Suci Engkau, maka peliharalah kami dari siksa neraka.

Ayat ini mengilustrasikan, bahwa dalam proses mengetahui (knowing) perlu dipakai satu proses tunggal tauhid. Karena secara histories, tauhid adalah fundamental Islam yang harus diaplikasikan dalam praktik kehidupan.

\section{Evaluasi}

Evaluasi adalah salah satu siasat yang dipergunakan oleh sesorang untuk mengukur atau menilai terhadap keberhasilan tugas atau kerjanya, dan untuk menentukan sikap dan tindak lanjutnya lagi. Oleh karena itu, Evaluator mestinya harus paham terhadap filsafat evaluasi itu, sehingga ia dapat melaksanakannya secara holistic-integralistik, tepat, akurat dan bernilai guna.

Evaluasi bila dilihat dalam ilmu pendidikan, ia berarti: The Act or prosses to determining the value of something (Edwind dan Gerald W. Brow Wand, 1957: 1). Yang memiliki arti seperangkat perbuatan atau proses untuk menentukan nilai sesuatu.

Filsafat evaluasi sangatlah penting untuk diketahui, karena dengan mengetahui itu, evaluator akan dapat menentukan berhasil atau tidaknya tugas atau kerja. Evaluasi yang dilakukan bisa saja dalam evaluasi ontologis, epistimologis, aksiologi, baik dalam rancangan, pelaksanaan dan evaluasi.

\section{KESIMPULAN}

Ilmu-ilmu pada asalnya satu dari satu sumber, yang Maha Sumber, Allah SWT. Ketika ilmu-ilmu itu turun dan diserap oleh manusia dengan serba keterbatasan. Ilmu-ilmu itu menjadi bercerai, karena dibatasi oleh manusia itu sendiri. Ia menilai dan menentukan menurut dirinya sendiri. Sehingga ilmu itu memeiliki ragam entitiasnya masing-masing menurut olahan otaknya dan tidak bersintuhan satu sama lain. Pendek kata Islam tidak masuk dalam ruang sains dan sains tidak masuk dalam ruang Islam.Ia berdiri sendiri-sendiri.

Agar tidak terlalu hanyut dalam belahan itu, agaknya perlu disiasati dengan arif agar ilmu yang terbelah itu dapat kembali ke pangkuan pertiwinya, Sang Pemilik Allah SWT. Maka perlu dilakukan rekonstruksi integritas sains dan Islam, terutama bagi praktisi pendidikan.

Sains adalah sebutan dalam bahasa Indonesia yang terambil dari tulisan bahasa Inggeris, yakni "science" yang artinya ilmu pengetahuan. Ilmu pengetahuan itu adalah ilmu alam semesta, baik yang ada di langit, di bumi maupun isinya. Islam adalah suatu sikap ber- 
serah diri atau taat secara ikhlas kepada Allah dengan mengikuti syari'at Nabi SAW. Yang berpedoman kepada alQur'an dan Hadits, demi mendapati kehidupan yang selamat dan sejahtera di dunia dan di akhirat. Islam adalah agama universal. Ia memiliki kandungan yang luas, dan syarat dengan nilai.

Menjadi guru bukanlah mudah. Pada dirinya sudah melekat persyaratan personaliti dan akademisi.

\section{DAFTAR RUJUKAN}

Departemen Agama RI., al-Qur'an dan Terjemahnya, Semarang: CV. Toha Putra, 1989.

A. Qodri Azizy. Melawan Globalisasi;Reintegrasi Ajaran Islam Persiapan SDM dan Terciptanya masyaakat Madani. Yokyakarta: Pustaka Pelajar, 2003.

- Pengembangan Ilmu-Ilmu KeIslaman. Semarang: Aneka Ilmu, 2004.

Cowie. AP At. All.Oxford Advanced Learn's dictionary.Oxford Universitas Dictionary, 1999.

Edwind dan Gerald W. Brow Wand. Essentials of Educational Evaluation.New Yor: Tp. 1957.

John M. Echols dan Hassan Shadily. Kamus Inggersi Indonesia. Jakarta: PT. Gramedia, 1996.

Daftar Indeks

biologi, 28, 31, 33

guru, 30, 31, 33, 36

pendidikan, 27, 28, 30, 31, 32, 33, 35
Bangunan teologi profetik reintegrasi sains dan Islam berawal dari dasar atau sendi interaksi yakni berasaskan sendi tunggal yaitu tauhid. Terus dilanjutkan dengan pemilihan materi dengan mengutaman al-Qur'an dan hadits sebagai fondamen awal. .Ilmu-ilmu sains dikemas dengan nilai nilai Qur'ani dan hadisi. Islam sebagai ethic, moralistic proses.

Louis Ma'luf. Al-Munjid fi al-Lughah wa al-A'lam. Beirut: Dar elMasreq, 1986.

M. Amin Abdullah dan Editor Jarot Wahyudi, M. Anas Amin dan Mustofa. Menyatukan Kembali Ilmu-Ilmu Agama dan Umum; Upaya Mempertemukan Epistemologi Islam dan Umum. Yogyakarta: Sunan Kalijaga Press, 2003.

Muhammad Rasyid Redha. Tafsir alManar. Kairo: Dar al-Fikr, t.th.

Nurcholis Madjid.Islam Agama Kemanusiaan.Jakarta: Paramadina, 1995.

Ramayulis. Ilmu Pendidikan Islam. Jakarta: Kalam Mulia, 2002.

Sayyid Quthb.Fi zhilal al-Qur'an. Kairo: Dar al-Syuruq, 1978.

praktisi, 27, 28, 30, 31, 32, 33, 36

sains, 27, 28, 29, 32, 33, 34, 35, 36 